\title{
Pedicle screw fixation and posterior fusion for lumbar degenerative diseases: effects on individual paraspinal muscles and lower back pain; a single-center, prospective study
}

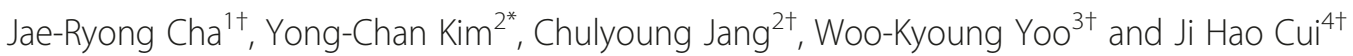

\begin{abstract}
Background: To the best of our knowledge, there have been no reports on the points at which the denervated multifidus and erector spinae muscles become reinnervated after pedicle screw fixation and posterior fusion in patients with lumbar degenerative diseases. Our study was designed to confirm reinnervation of denervated paraspinal muscles following pedicle screw fixation and posterior fusion and to confirm alleviation of the patients' lower back pain (LBP).

Methods: In this prospective study, we enrolled 67 patients who had undergone pedicle screw fixation and posterior fusion. The surgery had alleviated their leg pain, but the patients complained of LBP at the L3-5 level 3 months after the surgery. The patients were divided into two groups (I and II) according to the level at which pain was experienced. Paraspinal mapping scores were recorded preoperatively and 3, 6, 12, and 18 months postoperatively. Oswestry Disability Index and visual analogue scale scores were determined. Regression analyses using a general linear model and a mixed model were performed.

Results: Pedicle screw fixation and posterior fusion significantly denervated the multifidus and erector spinae not only in the surgical segment, but also in adjacent segments. Group I patients displayed reinnervation in the denervated erector spinae and multifidus muscles at 12 and 18 months, respectively. In contrast, group II showed reinnervation only in of the denervated erector spinae of the upper segment at 18 months, with no other areas of reinnervation. Postoperative LBP was significantly diminished at 12 months in group I and at 18 months in group II. There was also significantly less LBP at 6 months (prior to reinnervation of the paraspinal muscles).

Conclusions: The denervated multifidus and erector spinae muscles at L4-5, which had been denervated using pedicle screw fixation and posterior fusion, were significantly reinnervated at 18 months postoperatively, whereas patients with denervation at L3-5 had only a tendency to be reinnervated at follow-up. Postoperative LBP in these patients was significantly diminished at the follow-up visits.
\end{abstract}

Keywords: Pedicle screw fixation, Posterior fusion, Paraspinal muscle, Reinnervation, Lower back pain

\footnotetext{
* Correspondence: yckimspine@gmail.com

${ }^{\dagger}$ Equal contributors

2Department of Orthopaedic Surgery, Hallym University Sacred Heart

Hospital, Hallym University, 896 Pyeongchon-dong, Dongan-gu, Anyang-si,

South Korea

Full list of author information is available at the end of the article
}

\section{$\int$ Biomed Central}

(c) 2016 Cha et al. Open Access This article is distributed under the terms of the Creative Commons Attribution 4.0 international License (http://creativecommons.org/licenses/by/4.0/, which permits unrestricted use, distribution, and reproduction in any medium, provided you give appropriate credit to the original author(s) and the source, provide a link to the Creative Commons license, and indicate if changes were made. The Creative Commons Public Domain Dedication waiver (http://creativecommons.org/publicdomain/zero/1.0/) applies to the data made available in this article, unless otherwise stated. 


\section{Background}

Posterior spinal fusion, followed by instrumented spinal fusion, is the main strategy for treating degenerative lumbar disease (DLD). It is associated, however, with postoperative complications, such as lower back pain (LBP), which have been described in the literature [1-3]. Intraoperatively, muscle dissection from the vertebral processes and prolonged retraction cause ischemia and denervation of the paraspinal muscles, resulting in degenerative changes in these muscles and pain [4]. It has been reported that patients with chronic or postoperative LBP have less well developed paraspinal muscles than those in age-matched, normal, healthy individuals [5]. It has also been reported that there is a postoperative reduction in the cross-sectional area of paraspinal muscles, such as the multifidus [6]. One previous study showed atrophy of type II fibers and internal structural changes in type I fibers of multifidus muscles in these patients [7]. To date, there has been a persistent interest in postoperative changes in paraspinal muscles, including their decreased thickness on ultrasonography [8], edema and fat degeneration on magnetic resonance imaging (MRI) [9], and low myogenic potential on neurophysiological tests [10]. Others have reported that paraspinal muscles are vulnerable to denervation and atrophy because of their dissection and retraction and the immobilized spinal segment due to fusion during posterior spinal operations [11].

It remains uncertain, however, whether damaged paraspinal muscles can recover after posterior spinal surgery. In addition, there are no reports regarding the neurophysiology of paraspinal muscles at the surgical and adjacent levels.

Given this background, we set out to confirm (or deny) reinnervation of denervated paraspinal muscles after pedicle screw fixation and posterior fusion. We also wanted to compare the timing of reinnervation between the denervated multifidus and erector spinae depending on the surgical level in patients with a DLD. Finally, we analyzed the relation between the point at which postoperative LBP was alleviated and the point at which the denervated multifidus and erector spinae began reinnervation.

\section{Methods}

\section{Study population and design}

This study was approved by Forum for Ethical Review Committees in Asia \& the Western Pacific (FERCAP). A written informed consent was obtained from all participants in this study. We enrolled a total of 67 patients whose leg pain had been alleviated by pedicle screw fixation and posterior fusion at the L3-5 level at our institution between July 2009 and November 2012 but who now, 3 months later, complained of LBP. The patients were followed up for a minimum of 18 months. This clinical series of patients comprised 15 men and 52 women (mean age 62.2 years, range $41-82$ years; mean body mass index $24.4 \mathrm{~kg} / \mathrm{m}^{2}$, range $19.4-33.5 \mathrm{~kg} / \mathrm{m}^{2}$ ). Their underlying diseases included 54 cases of spinal stenosis and 13 cases of spondylolisthesis.

The patients were divided into two groups depending on the surgical level: group I (36 patients), who had undergone pedicle screw fixation and posterior fusion after total facetectomy at the L4-5 level; and group II (31 patients), who had undergone pedicle screw fixation and posterior fusion after total facetectomy at the L3-5 level. All surgical dissections were performed via a midline posterior approach, with the same retractor used to expose the surgical field.

The study was designed to analyze paraspinal muscles (e.g., multifidus and erector spinae) at three spinal levels: the surgical segment (L4-5 in both groups), upper segment (L3-4 in group I and L2-3 in group II), and lower segment (L5-S1 in both groups). To evaluate changes in paraspinal muscles at 3,6,12, and 18 months postoperatively-compared with that preoperatively-electromyography (EMG) was performed according to the guidelines of the American Association of Electrodiagnostic Medicine using the NeuroScreen (Jaeger-Toennies, Würzburg, Germany). To quantify any abnormal spontaneous activity, we performed paraspinal mapping. In addition, we undertook simplified mini-paraspinal mapping [12]. The positive sharp wave, fibrillation potential, complex repetitive discharge, and fasciculation potential were recorded on both sides and then averaged. Measurements were evaluated based on five grades $(0,1+, 2+, 3+, 4+)$ (Table 1$)$. Thus, we compared the degree of denervation of the multifidus and erector spinae muscles at $3,6,12$, and 18 months postoperatively compared with that observed preoperatively.

To assess the multifidus at each segment, the sites of needle insertion were marked in the region $2.5 \mathrm{~cm}$ lateral and $1 \mathrm{~cm}$ cranial to the inferior border of the spinous process of the lower lumbar interbody (Fig. 1). As a

Table 1 Paraspinal mapping scoring system for points of insertion

\begin{tabular}{ll}
\hline Score & Criteria \\
\hline 0 & No reliable data obtained \\
- & No reproducible spontaneous activity \\
+ & A single, reproducible train of fibrillation potentials \\
++ & More than one train of fibrillation potentials \\
+++ & Numerous fibrillation potentials at more than one depth \\
++++ & Fibrillation potentials fill the screen \\
\hline
\end{tabular}

${ }^{a}$ Two or more motor units are interfering with inspection for possible waves, the insertion contracting the bone before contracting muscle, or adipose depth being greater than needle length

${ }^{b}$ No consideration for spontaneous activity in association with periosteum or motor end-plate noise 


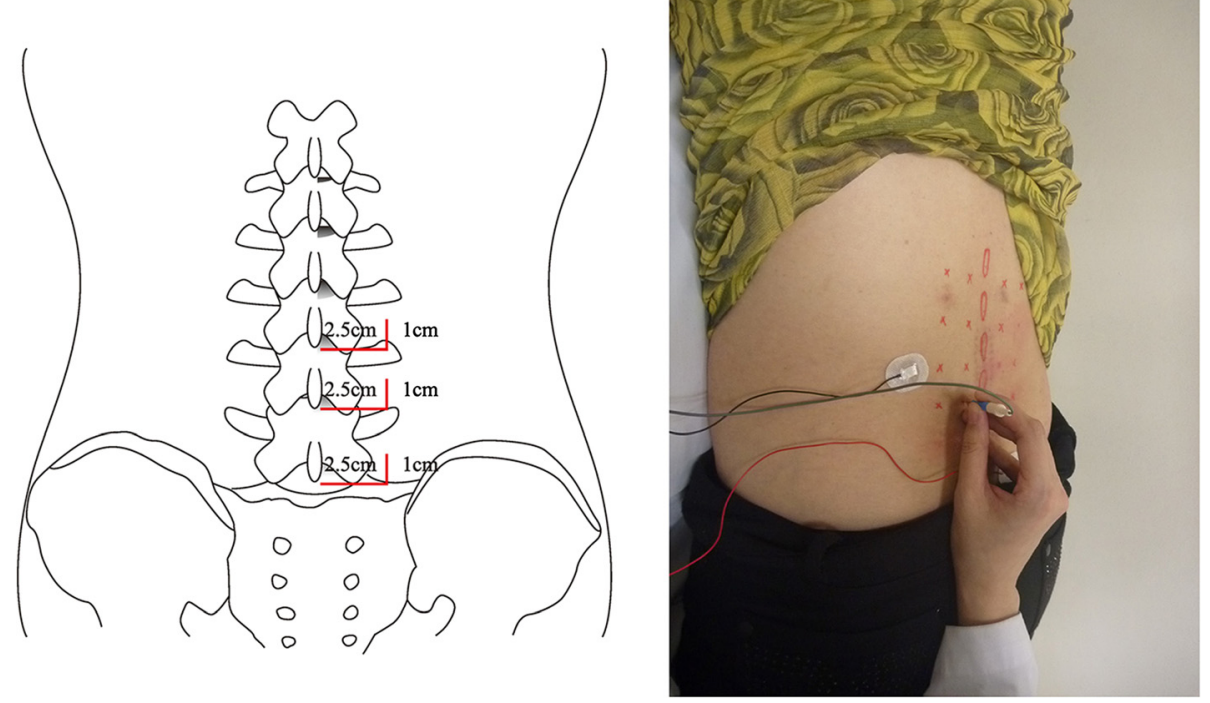

Fig. 1 Placement of the needle from the surgical level to adjacent segments from the posterior view of the lumbar spine

landmark for surgical removal during the decompression procedure at the L4 spinous process, we set the midpoint between the spinous process of L3 and L5. When the depth of insertion reached $40 \mathrm{~mm}$, we considered that the needles were inserted into the multifidus muscle. (Severely obese patients were excluded from the current study.) We then, again, placed the needle in the cranial direction at an angle of $45^{\circ}$ and in the caudal direction at an angle of $45^{\circ}$ toward the midline. To ensure access to the erector spinae, we placed the needle in the cranial direction at an angle of $45^{\circ}$ and in the caudal direction at an angle of $45^{\circ}$ from the midline, as previously. We then confirmed these landmarks on ultrasonography.

We also evaluated clinical outcomes, except for leg pain, based solely on the LBP, using both the visual analogue scale (VAS) and the Oswestry Disability Index (ODI) preoperatively and at 3, 6, 12, and 18 months postoperatively. We did not use the ODI to evaluate the patients' sexual activity.

\section{Statistical analysis}

Statistical analysis was done using SPSS version 10.0 for Windows software (SPSS Inc., Chicago, IL, USA). For statistical analysis, we performed a regression analysis of descriptive variables and a mixed model analysis preoperatively and at 3, 6, 12, and 18 months postoperatively. We also performed a Mann - Whitney test to analyze differences in variables between the upper, surgical, and lower segments. A value of $P<0.05$ was considered to indicate statistical significance.

\section{Results}

\section{Changes in the multifidus muscle on EMG}

In group I, denervation in the upper segment of the multifidus muscle was $0.66+$ preoperatively, $1.91+$ at 3 months, $1.83+$ at 6 months, $1.62+$ at 12 months, and $0.72+$ at 18 months. In the multifidus surgical segment, they were, respectively, $1.01+, 2.59+, 2.58+, 2.31+$, and $1.08+$. The corresponding values in the multifidus lower segment were $0.93+, 2.50+, 2.40+, 2.11+$, and $0.89+$, respectively. These results indicate that there was reinnervation of the denervated multifidus at the surgical and adjacent segments at 18 months in group I (Table 2) (Fig. 2).

In group II, denervation in the multifidus muscle at the upper segment was $0.58+$ preoperatively, $2.19+$ at 3 months, $2.14+$ at 6 months, $2.22+$ at 12 months, and $1.37+$ at 18 months. The corresponding values in the multifidus surgical segment were $0.96+, 2.75+, 2.83+$, $2.63+$, and $2.03+$, respectively. In the multifidus lower segment, they were $0.89+, 2.53+, 2.58+, 2.53+$, and $1.87+$, respectively. These results indicate that there was no reinnervation of the denervated multifidus in the surgical and adjacent segments at 18 months in group II (Table 3) (Fig. 3).

\section{Changes in the erector spinae on EMG}

In group I, denervation of the erector spinae upper segment was $0.64+$ preoperatively, $1.75+$ at 3 months, $1.58+$ at 6 months, $0.70+$ at 12 months, and $0.67+$ at 18 months. The corresponding values in the surgical segment were $1.05+, 2.25+, 2.05+, 1.23+$, and $0.99+$, respectively. The values in the lower segment were $0.82+$, 
Table 2 Paraspinal mapping scores for group I

\begin{tabular}{|c|c|c|c|c|c|}
\hline Segment & Preop & PO\#3 M ( $P$ value) & PO\#6 M ( $P$ value) & PO\#12 M ( $P$ value) & PO\#18 M ( $P$ value) \\
\hline \multicolumn{6}{|c|}{ Multifidus muscle } \\
\hline Upper & $0.66 \pm 0.60$ & $1.91 \pm 0.88(<0.0001)$ & $1.83 \pm 1.01(<0.0001)$ & $1.62 \pm 1.11(<0.0001)$ & $0.72 \pm 0.49(0.5324)$ \\
\hline Surgical & $1.01 \pm 0.61$ & $2.59 \pm 1.03(<0.0001)$ & $2.58 \pm 1.19(<0.0001)$ & $2.31 \pm 1.01(<0.0001)$ & $1.08 \pm 0.62(0.5824)$ \\
\hline Lower & $0.93 \pm 0.74$ & $2.50 \pm 0.89(<0.0001)$ & $2.40 \pm 1.05(<0.0001)$ & $2.11 \pm 1.19(<0.0001)$ & $0.89 \pm 0.64(0.4251)$ \\
\hline \multicolumn{6}{|c|}{ Erector spinae muscle } \\
\hline Upper & $0.64 \pm 0.61$ & $1.75 \pm 0.78(<0.0001)$ & $1.58 \pm 0.75(<0.0001)$ & $0.70 \pm 0.52(0.5187)$ & $0.67 \pm 0.59(0.8027)$ \\
\hline Surgical & $1.05 \pm 0.55$ & $2.25 \pm 1.01(<0.0001)$ & $2.05 \pm 0.98(<0.0001)$ & $1.23 \pm 0.60(0.2155)$ & $0.99 \pm 0.65(0.6412)$ \\
\hline Lower & $0.82 \pm 0.71$ & $2.20 \pm 0.84(<0.0001)$ & $1.92 \pm 0.80(<0.0001)$ & $1.02 \pm 0.81(0.6029)$ & $0.85 \pm 0.64(0.8684)$ \\
\hline
\end{tabular}

Statistical significance at $P<0.05$

The upper segment indicates L3-4 in group I and L2-3 in group II; surgical segment indicates L4-5; lower segment, L5-S1, respectively

Preop and POM 3, 6, 12, and 18 indicate "preoperatively" and "at 3, 6, 12, and 18 months, postoperatively," respectively

$2.20+, 1.92+, 1.02+$, and $0.85+$, respectively. These results indicate that, in group I, there was reinnervation of the denervated erector spinae in the surgical and adjacent segments at 12 months (Table 2) (Fig. 4).

In group II, denervation of the erector spinae in the upper segment was $0.79+$ preoperatively, $1.94+$ at 3 months, $1.81+$ at 6 months, $1.72+$ at 12 months, and $1.06+$ at 18 months. In the surgical segment, the corresponding values were $0.85,2.57+, 2.58+, 2.42+$, and 1.49 + , respectively. The values in the lower segment were $0.83+, 2.33+, 2.51+, 2.33+$, and $1.42+$, respectively. These results indicate that, in group II, there was reinnervation only in the denervated erector spinae of the upper segment at 18 months (Table 3) (Fig. 5).

\section{Changes in LBP}

In group I, the mean VAS/ODI scores were 4.49/15.14 preoperatively, $6.95 / 25.42$ at 3 months, $4.77 / 14.29$ at 6 months, $1.21 / 4.99$ at 12 months, and $0.67 / 1.89$ at 18 months. In group II, these values were 4.11/14.06,
$7.28 / 28.00,6.39 / 24.17,5.61 / 19.28$, and $3.44 / 9.17$, respectively (Table 4). These results indicate that there was significant aggravation of LBP in both groups immediately postoperatively. However, there was also significant alleviation of LBP at 12 months in group I and at 18 months in group II. In addition, there was significantly less LBP at 6 months (prior to reinnervation) in paraspinal muscles.

\section{Changes in paraspinal muscles in adjacent segments}

In group I, there was a significant difference in the degree of changes in multifidus and erector spinae muscles between the upper and lower segments at 3, 6, and 12 months postoperatively $(P<0.05)$. There were no such differences at 18 months, however $(P=0.0923$ and $P=0.1042$, respectively) (Figs. 2, 4).

In group II, there was a significant difference in the degree of changes in the multifidus and erector spinae muscles between the upper and lower segments at 3, 6, 12 , and 18 months postoperatively $(P<0.05)$ (Figs. 3,5$)$.

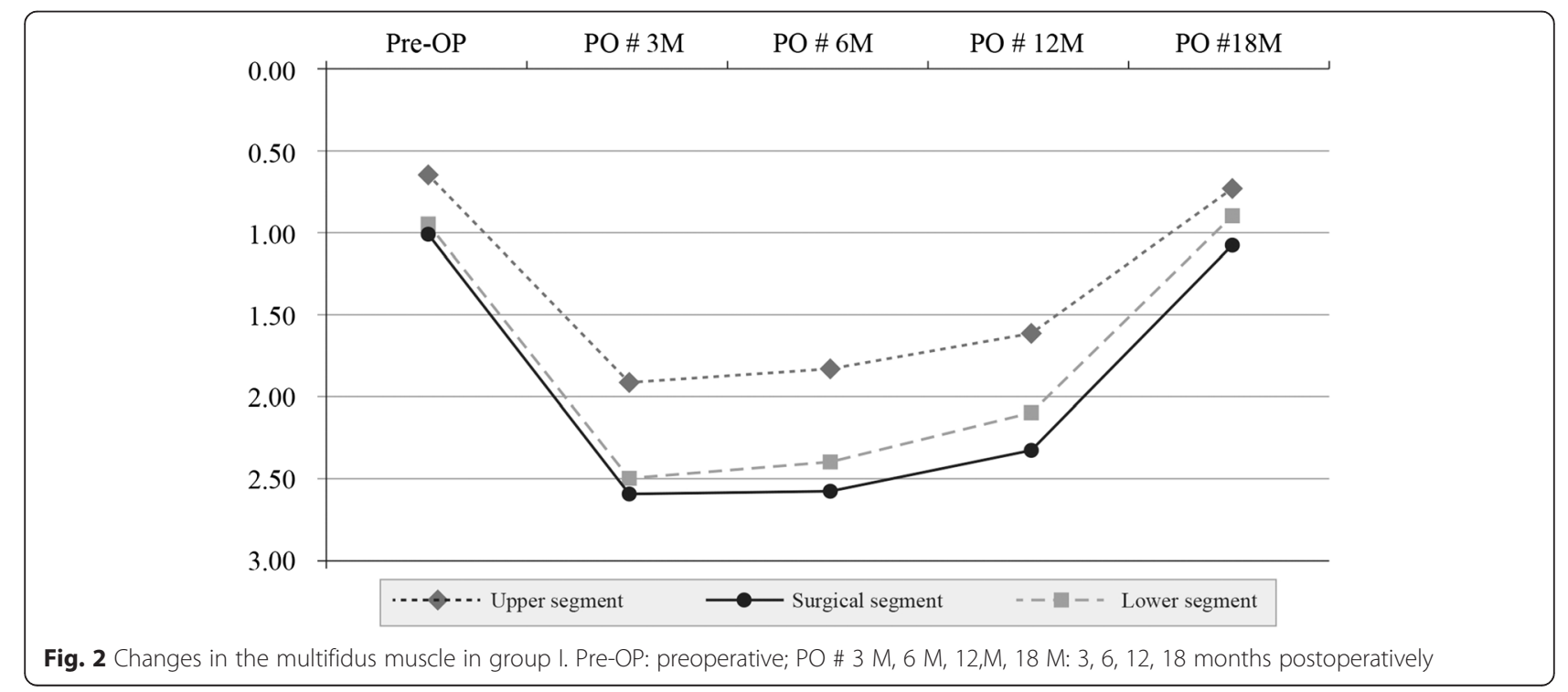


Table 3 Paraspinal mapping scores for group II

\begin{tabular}{llllll}
\hline Segment & Preop & PO\#3 M $(P$ value $)$ & PO\#6 M $(P$ value $)$ & PO\#12 M $(P$ value $)$ & $P O \# 18$ M $(P$ value $)$ \\
\hline Multifidus muscle & & & & & \\
$\quad$ Upper & $0.58 \pm 0.81$ & $2.19 \pm 1.04(<0.0001)$ & $2.14 \pm 0.87(<0.0001)$ & $2.22 \pm 0.96(<0.0001)$ & $1.37 \pm 0.88(0.0352)$ \\
$\quad$ Surgical & $0.96 \pm 0.81$ & $2.75 \pm 0.71(<0.0001)$ & $2.83 \pm 0.69(<0.0001)$ & $2.63 \pm 0.98(<0.0001)$ & $2.03 \pm 0.82(<0.0001)$ \\
$\quad$ Lower & $0.89 \pm 0.85$ & $2.53 \pm 1.03(<0.0001)$ & $2.58 \pm 0.97(<0.0001)$ & $2.53 \pm 1.05(<0.0001)$ & $1.87 \pm 0.74(<0.0001)$ \\
Erector spinae muscle & & & & & $1.72 \pm 1.16(0.0012)$ \\
$\quad$ Upper & $0.79 \pm 0.70$ & $1.94 \pm 0.95(<0.0001)$ & $1.81 \pm 0.79(<0.0001)$ & $1.06 \pm 0.41(0.0895)$ \\
$\quad$ Surgical & $0.85 \pm 0.66$ & $2.57 \pm 0.73(<0.0001)$ & $2.58 \pm 0.75(<0.0001)$ & $2.42 \pm 0.81(<0.0001)$ & $1.49 \pm 0.60(0.0312)$ \\
Lower & $0.83 \pm 0.70$ & $2.33 \pm 0.83(<0.0001)$ & $2.51 \pm 1.01(<0.0001)$ & $2.33 \pm 0.93(<0.0001)$ & $1.42 \pm 0.42(0.0122)$ \\
\hline
\end{tabular}

Statistical significance at $P<0.05$

The upper segment indicates L3-4 in group I and L2-3 in group II; surgical segment indicates L4-5; lower segment, L5-S1, respectively

Preop and POM 3, 6, 12, and 18 indicate "preoperatively" and "at 3, 6, 12, and 18 months, postoperatively," respectively

It is of note that there was slight damage to both the multifidus and erector spinae muscles in the upper segment during surgery. Reinnervation occurred earlier in the upper segments than in the lower segments.

\section{Discussion}

It is widely known that patients undergoing lumbar surgery are at increased risk of developing atrophy of the lumbar extensors [13]. Yong et al., who conducted an animal study to compare a fusion group and a control group, reported that there was a significant decrease in the root mean square (RMS) and median frequency (MF) - which served as indicators of the activity of paraspinal muscles-in the fusion group at the 6-month follow-up when compared with the preoperative values. These authors also showed that histologically there was also a significant decrease in the volume of muscle fibers, which served as an indicator of amyotrophy [14]. A more recent human study observed significantly increased denervation at the 6-month follow-up [15]. Our study showed similar results in that both multifidus and erector spinae muscles were still significantly denervated at the 6-month follow-up (compared with their preoperative status). In terms of the changes in adjacent levels, Yong et al. reported that there was a significant increase in the RMS and MF of paraspinal muscles at the adjacent cranial and caudal levels when compared with those that had been subjected to surgery [14]. The current study, however, demonstrated that there was a significant difference in the degree of change in multifidus and erector spinae muscles between the adjacent cranial and caudal levels. We think it may result from the different subjects being studied (adult New Zealand white rabbits versus adult humans), the degree of damage to the paraspinal muscles, and the fusion level.

For the purpose of avoiding a bias when evaluating the degree of denervation in the paraspinal muscles on EMG, we limited the spinal levels to L3-5. There were significant degrees of denervation in the paraspinal muscles at the surgical level and its adjacent levels at

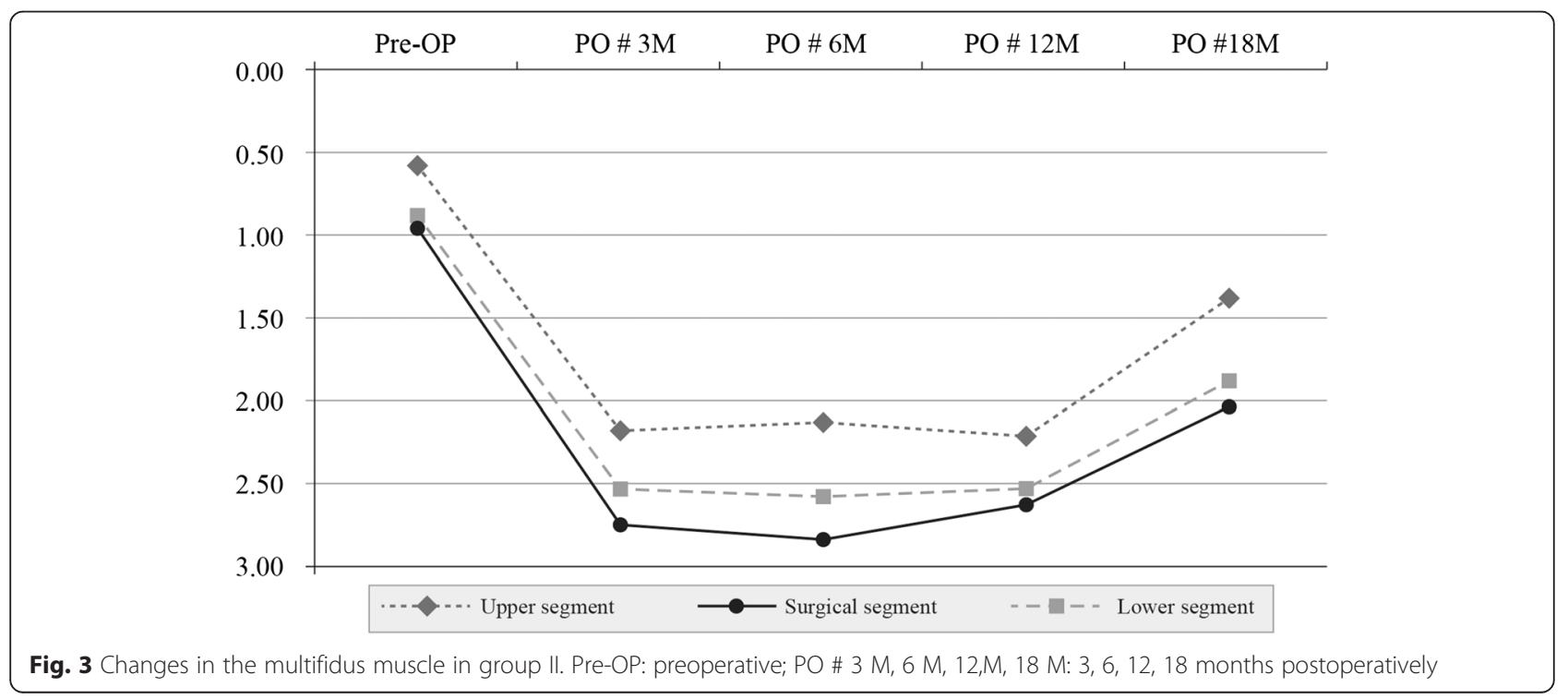




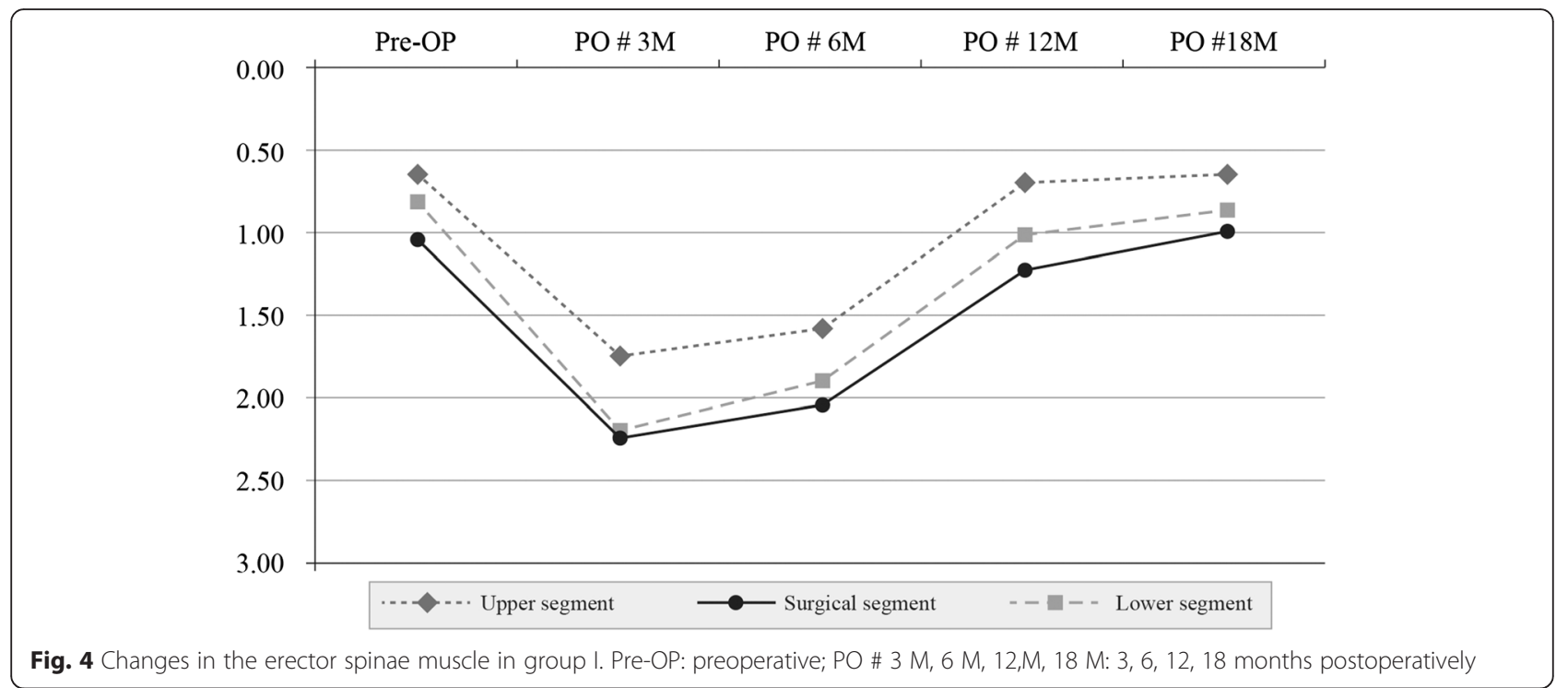

3 months. This might be due to the retraction, compression, and intraoperative damage to the posterior primary ramus and disuse muscle atrophy due to fusion and orthoses.

Waschke et al. demonstrated there was slightly decreased denervation at the 12-month follow-up in adult humans [15]. In the current study, we found that, in group I, there was more rapid reinnervation in the upper spinal segments that at other levels. This might be due to technical problems such as less traction, less severe direct damage to paraspinal muscles during dissection, and a smaller area of the multifidus being removed. We also assumed that a greater amount of paraspinal muscles' dissection in the cranial and lateral directions and a more immobilized spinal segment might lead to slower reinnervation in group II than in group I.
In group II, although there was no significant reinnervation of the denervated multifidus and erector spinae muscles until the 18-month follow-up, the upper segment of the denervated erector spinae was significantly reinnervated at 18 months. Also, the other muscles of each segment had a tendency to be reinnervated during serial follow-up evaluations. These results suggest that the postoperative denervation in paraspinal muscles resulting from one- and two-level pedicle screw fixation and posterior fusion might not be a permanent phenomenon. Further studies are therefore warranted to confirm the significant reinnervation of paraspinal muscles following multiple levels of pedicle screw fixation and fusion.

In the current study, we assumed that the degrees of reinnervation in denervated erector spinae and multifidus

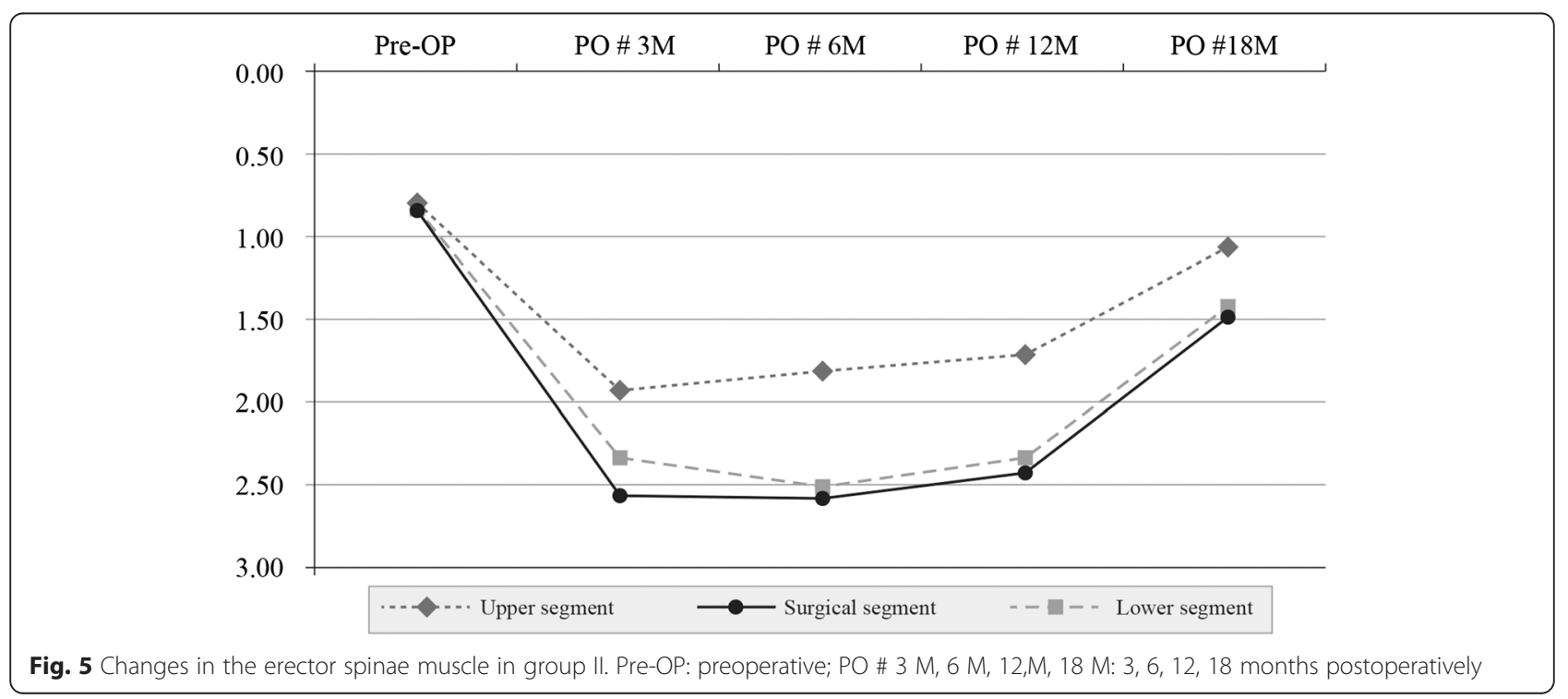


Table 4 Changes in lower back pain for each group: significance (P)

\begin{tabular}{|c|c|c|c|c|c|}
\hline Parameter & Preop & PO\#3 M & PO\#6 M & PO\#12 M & PO\#18 M \\
\hline \multicolumn{6}{|l|}{ Group I } \\
\hline VAS & $4.49 \pm 0.65$ & $6.95 \pm 0.84$ & $4.77 \pm 1.12$ & $1.21 \pm 0.66$ & $0.67 \pm 0.54$ \\
\hline Preop vs PO & & $<0.0001$ & 0.0620 & $<0.0001$ & $<0.0001$ \\
\hline Previous $\mathrm{PO}$ vs ultimate $\mathrm{PO}$ & & & 0.0047 & $<0.0001$ & 0.0325 \\
\hline ODI & $15.14 \pm 3.93$ & $25.42 \pm 3.47$ & $14.29 \pm 4.25$ & $4.99 \pm 2.33$ & $1.89 \pm 0.48$ \\
\hline Preop vs PO & & $<0.0001$ & 0.7530 & $<0.0001$ & $<0.0001$ \\
\hline Previous PO vs ultimate $\mathrm{PO}$ & & & $<0.0001$ & $<0.0001$ & $<0.0001$ \\
\hline \multicolumn{6}{|l|}{ Group ॥ } \\
\hline VAS & $4.11 \pm 0.90$ & $7.28 \pm 0.75$ & $6.39 \pm 1.38$ & $5.61 \pm 1.65$ & $3.44 \pm 1.69$ \\
\hline Preop vs PO & & $<0.0001$ & 0.0110 & 0.0390 & 0.0414 \\
\hline Previous PO vs ultimate $\mathrm{PO}$ & & & 0.5540 & 0.8750 & 0.0120 \\
\hline ODI & $14.06 \pm 2.58$ & $28.00 \pm 4.78$ & $24.17 \pm 4.64$ & $19.28 \pm 3.79$ & $9.17 \pm 3.76$ \\
\hline Preop vs PO & & $<0.0001$ & $<0.0001$ & 0.0012 & $<0.0001$ \\
\hline Previous $\mathrm{PO}$ vs ultimate $\mathrm{PO}$ & & & 0.0310 & 0.0210 & $<0.0001$ \\
\hline
\end{tabular}

Preop and POM 3, 6, 12, and 18 indicate "preoperatively" and "at 3, 6, 12, and 18 months, postoperatively," respectively. PO indicates postoperative, VAS visual analogue scale, ODI Oswestry Disability Index

muscles at the 12- and 18-month follow-up evaluations provide evidence that muscle function is likely to recover to the preoperative level even in patients undergoing an instrumentation and fusion procedure.

As described by Macintosh and Bogduc, there is limited evidence to explain the correlation between denervated paraspinal muscles and failed back surgery syndrome (FBSS) in patients undergoing posterior lumbar surgery [16]. In contrast, there are many reasons for an unsatisfactory clinical outcome after posterior instrumentation and fusion of the lumbar spine. Among them, dysfunction of the paraspinal muscles due to atrophy is one of the most discussed issues [17]. Sihvonen et al. reported that the degree of denervation in paraspinal muscles was significantly greater in patients with FBSS than in those with satisfactory surgical outcomes [6]. Ranaten et al. also suggested that inactivation of and damage to axons might be associated with atrophy of type 2 muscle fibers and unsatisfactory clinical outcomes [18]. Wilbourne and Aminoff demonstrated that denervation of paraspinal muscles leads to significant changes in spinal biomechanics, which could cause LBP [19]. In terms of the clinical consequence of denervation of paraspinal muscles, the current study showed results similar to those reported for previous studies.

Moreover, there was significant alleviation of LBP at the 12-month follow-up in group I and at the 18-month follow-up in group II. Thus, the LBP diminishes prior to reinnervation in denervated paraspinal muscles.

\section{Conclusions}

The denervated multifidus and erector spinae accomplished by pedicle screw fixation and posterior fusion at L4-5 had significantly reinnervated at 18 months, and those at L3-5 had a tendency to be reinnervated at longer follow-up intervals. Postoperative LBP in these patients was significantly diminished at follow-up evaluations, but prior to reinnervation in denervated paraspinal muscles.

\section{Consent}

A written informed consent was obtained from all the participants in this study.

\section{Abbrevations}

DLD: Degenerative lumbar disease; LBP: Lower back pain; MRI: Magnetic resonance imaging; FERCAP: Forum for Ethical Review Committees in Asia \& the Western Pacific; EMG: Electromyography; BMI: Body mass index; VAS: Visual Analogue Scale; ODI: Oswestry Disablity Index; RMS: Root mean square; MF: Median frequency; FBSS: Failed back surgery syndrome.

\section{Competing interests}

We declare that none of the authors have any competing interests.

\section{Authors' contributions}

JRC and YCK planned and designed this study and wrote and translated this article. WKY performed electromyographic examinations. CYJ and JHC gathered data of patients and created figures and tables. JHC participated in the statistical analysis. All authors read and approved the final manuscript.

\section{Authors' information}

Yong-Chan Kim is a Professor in the Department of Orthopaedic Surgery, Hallym University Sacred Heart Hospital, Hallym University.

Jae-Ryong Cha is an Associate Professor in the Department of Orthopaedic Surgery, Ulsan University Hospital, College of Medicine, Ulsan University.

Woo-Kyoung Yoo is a Professor in the Department of Physical Medicine and Rehabilitation, Hallym University Sacred Heart Hospital, College of Medicine, Hallym University.

Chulyoung Jang is a Medical Resident in the Department of Orthopaedic Surgery, Hallym University Sacred Heart Hospital, Hallym University.

Ji Hao Cui is an Associate Professor in the Department of Orthopaedic

Surgery, the Fourth Affiliated Hospital of Guangzhou Medical University, 195,

Dongfeng Xi Road, Guangshou, China 


\section{Acknowledgments}

Each author certifies that he or a member of his immediate family has no funding or commercial associations (e.g., consultancies, stockownership, equity interest, patent/licensing arrangements, etc.) that might pose a conflict of interest in connection with the submitted article. The researchers are indebted to the participants for their willingness to participate in the study.

\section{Author details}

'Department of Orthopedic Surgery, Ulsan University Hospital, College of Medicine, Ulsan University, 290-3 Cheonha-Dong, Ulsan-si, Dong-Ku, South Korea. ${ }^{2}$ Department of Orthopaedic Surgery, Hallym University Sacred Heart Hospital, Hallym University, 896 Pyeongchon-dong, Dongan-gu, Anyang-si, South Korea. ${ }^{3}$ Department of Physical Medicine and Rehabilitation, Hallym University Sacred Heart Hospital, College of Medicine, Hallym University, 896 Pyeongchon-dong, Dongan-gu, Anyang-si, South Korea. ${ }^{4}$ Department of Orthopaedic Surgery, The Fourth Affiliated Hospital of Guangzhou Medical University, 195 Dongfeng Xi Road, Guangshou, China.

\section{Received: 24 February 2015 Accepted: 4 February 2016}

\section{0.}

\section{References}

1. Helenius I, Remes V, Yriönen T, Ylikoski M, Schlenzka D, Helenius M, et al. Comparison of long-term functional and radiologic outcomes after Harrington instrumentation and spondylodesis in adolescent idiopathic scoliosis: a review of 78 patients. Spine (Phila Pa 1976). 2002;27:176-80.

2. Kennelly KP, Stokes MJ. Pattern of asymmetry of paraspinal muscle slice in scoliosis examined by ultrasound imaging. Spine (Phila Pa 1976). 1993;18:913-7.

3. Winter RB, Smith MD, Lonstein JE. Congenital scoliosis due to unilateral unsegmented bar: posterior spine fusion at age 12 months with 44-year follow-up. Spine (Phila Pa 1976). 2004;29:E52-5.

4. Hyun SJ, Kim YB, Kim US, Park SW, Nam TK, Hong HJ, et al. Postoperative changes in paraspinal muscle volume: comparison between paramedian interfascial and midline approaches for lumbar fusion. J Korean Med Sci. 2007:22:646-51.

5. Hodges PW, Richardson CA. Inefficient muscular stabilization of the lumbar spine associated with low back pain: a motor control evaluation of transversus abdominis. Spine (Phila Pa 1976). 1996;21:2640-50.

6. Sihvonen T, Herno A, Paljärvi L, Airaksinen O, Partanen J, Tapaninaho A. Local denervation atrophy of paraspinal muscles in postoperative failed back syndrome. Spine (Phila Pa 1976). 1993;18:575-81.

7. Mattila M, Hurme M, Alaranta H, Paljärvi L, Kalimo H, Falck B, et al. The multifidus muscle in patients with lumbar intervertebral disc herniation. Spine (Phila Pa 1976). 1986;11:732-8.

8. Suwa H, Hanakita J, Ohshita N, Gotoh K, Matsuoka N, Morizane A. Postoperative changes in paraspinal muscle thickness after various lumbar back surgery procedures. Neurol Med Chir (Tokyo). 2000;40:151-4. discussion 154-5.

9. Kuroki H, Tajima N, Kubo S. Clinical results of posterolateral fusion for degenerative lumbar spinal diseases: a follow-up study of more than 10 years. J Orthop Sci. 2002;7:317-24.

10. Kramer M, Katzmaier P, Eisele R, Ebert V, Kinzl L, Hartwig E. Surface electromyographic-verified muscle damage associated with the open dorsal approach to the lumbar spine. Eur Spine J. 2001;10:414-20.

11. Weiner BK, Walker M, Brower RS, McCulloch JA. Microdecompression for lumbar spinal canal stenosis. Spine (Phila Pa 1976). 1999;24:2268-72.

12. Haig AJ. Clinical experience with paraspinal mapping. I: Neurophysiology of the paraspinal muscles in various spinal disorders. Arch Phys Med Rehabil. 1997;78:1177-84

13. Mayer TG, Vanharanta H, Gatchel RJ, Mooney V, Barnes D, Judge L, et al. Comparison of $\mathrm{CT}$ scan muscle measurements and isokinetic trunk strength in postoperative patients. Spine (Phila Pa 1976). 1989;14:33-6.

14. Hu Y, Leung HB, Lu WW, Luk KD. Histologic and electrophysiological changes of the paraspinal muscle after spinal fusion: an experimental study. Spine (Phila Pa 1976). 2008;33:1418-22.

15. Waschke A, Hartmann C, Walter J, Dünisch P, Wahnschaff F, Kalff R, et al. Denervation and atrophy of paraspinal muscles after open lumbar interbody fusion is associated with clinical outcome-electromyographic and
CT-volumetric investigation of 30 patients. Acta Neurochir (Wien) 2014:156:235-44.

16. Macintosh JE, Bogduk N. 1987 Volvo award in basic science: the morphology of the lumbar erector spinae. Spine. 1987;12:658-68.

17. Lu WW, Hu Y, Luk KD, Cheung KM, Leong JC. Paraspinal muscle activities of patients with scoliosis after spine fusion: an electromyographic study. Spine (Phila Pa 1976). 2002;27:1180-5.

18. Ranaten J, Hurme M, Falck B, Alaranta H, Nykvist F, Lehto M, et al. The lumbar multifidus muscle five years after surgery for a lumbar intervertebral disc herniation. Spine (Phila Pa 1976). 1993;18:568-74.

19. Wilbourne AJ, Aminoff MJ. The electrophysiologic examination in patients with radiculopathies. Muscle Nerve. 1988;11:1101-4.

\section{Submit your next manuscript to BioMed Central and we will help you at every step:}

- We accept pre-submission inquiries

- Our selector tool helps you to find the most relevant journal

- We provide round the clock customer support

- Convenient online submission

- Thorough peer review

- Inclusion in PubMed and all major indexing services

- Maximum visibility for your research

Submit your manuscript at www.biomedcentral.com/submit
Biomed Central 